\title{
A RECONFIGURAÇÃO DO CONCEITO DE SINCERIDADE EM TEORIAS PÓS-MODERNAS
}

\author{
Profa. Dra. Carla Milani Damião
}

RESUMO: O tema da sinceridade está intimamente relacionado com a subjetividade moderna e ao gênero autobiográfico iniciado, na filosofia, por Rousseau. Os pressupostos deste conceito serão apresentados brevemente para que possamos perceber o ressurgimento da sinceridade no contexto das teorias culturais pós-modernas de Lionel Trilling e de Charles Taylor. Das aulas de Trilling entre 1969 e 1970, publicadas sob o título de Sinceridade e autenticidade em 1972, à palestra de Taylor intitulada Ética da autenticidade, publicada em 1995, há uma considerável manifestação artística, na literatura, música, artes visuais e cinema, em torno da sinceridade e da autenticidade. A reconfiguração do conceito moderno de sinceridade e seu desdobramento como autenticidade, transforma o termo "autêntico" nas artes, conferindo-lhe uma acepção moral. Propomos, neste artigo, investigar o desdobramento do conceito de autenticidade com valor moral e não apenas artístico.

PALAVRAS-CHAVE: Sinceridade; Autenticidade; Subjetividade; Artes.

ABSTRACT: Sincerity is closely related to modern subjectivity and to the autobiographical genre, started in philosophy by 
Rousseau. The assumptions of this concept will be briefly presented in order to search for the resurgence of sincerity in the context of the postmodern cultural theories of Lionel Trilling and Charles Taylor. From Trilling's Harvard lectures, between 1969 and 1970, published two years later as Sincerity and Authenticity, to Taylor's conference entitled Ethics of Authenticity, published in 1995, there is considerable artistic expression in literature, music, visual arts and cinema concerned with sincerity and authenticity. The reframing of the modern concept of sincerity as authenticity transforms the term "authentic" in the arts, giving it a moral sense. We propose in this article to investigate the unfolding of the concept of authenticity with moral and not only artistic value.

KEYWORDS: Sincerity; Authenticity; Subjectivity; Arts. 


\section{INTRODUÇÃO}

Podemos afirmar que a sinceridade situa-se na encruzilhada de diferentes caminhos: o moral, o religioso e o estético, ao associar-se com a expressão literária e com a filosofia, se tivermos em vista a relação com a verdade e com a constituição da subjetividade que, ao narrar, se expõe ao outro. É, contudo, um conceito frágil, pouco definido e sempre sob suspeita, frequentemente associado ao culto da espontaneidade ${ }^{2}$.

Jean-Jacques Rousseau é conhecido como a principal referência à invenção da escrita autobiográfica no século XVIII, sendo, em seguida, acusado de criar, nesse tipo de narrativa, o culto de si mesmo. A subjetividade extrema, no entanto, é rompida quando o filósofo assina suas Confissões como cidadão de Genebra, marcando o aspecto político de sua narrativa e não apenas a afirmação de uma individualidade.

$\mathrm{O}$ valor da sinceridade em Rousseau pode ser entendido pelas seguintes máximas: Intus et in cute $e^{3}$, um conhecimento profundo de si mesmo; e Vitam impendere vero, o amor à verdade e o compromisso com Deus (natureza) e o leitor ${ }^{4}$.

$\mathrm{O}$ conhecimento de si mesmo equivale à narrativa sincera, transparente e verdadeira. Este conhecimento, metaforicamente, caracteriza-se como a "estética do coração", em outras palavras, a narrativa da sinceridade que pressupõe o conhecimento de si mesmo ao dizer: "sinto meu coração". Além disso, Rousseau lança um desafio a seus leitores: "Dou começo a uma empresa de que não há exemplos e cuja execução não terá imitadores. Quero mostrar aos meus semelhantes um homem em toda verdade de sua natureza; e serei eu esse homem" (ROUSSEAU, 1959, p.11).

No entanto, ao mesmo tempo em que Rousseau inaugura uma espécie de tormento do ser sincero na narrativa autobiográfica 
e impregna toda a escrita posterior deste tipo, a empresa do ser totalmente sincero apresenta-se a ele mesmo como uma tarefa difícil. Em A Nova Heloísa, Rousseau diz: "Você gostaria que fossemos sempre consistentes. Eu duvido que isso seja possível. Mas uma coisa é possível, ser sempre verdadeiro. Isso é o que quero ser". "Ser verdadeiro" não significa ser fiel aos fatos ou às pessoas, mas a uma verdade superior comandada pelo sentimento interior que está mais próximo da natureza. $\mathrm{O}$ contrário, "não ser verdadeiro" provém do embaraço, da distância que se tem de si diante dos outros, por conta da artificialidade criada pela convenção social. É o que Rousseau nos diz na "Quarta Caminhada" dos Devaneios de um caminhante solitário, discriminando a verdade que interessa à justiça e a "verdade" da ficção. A primeira, trata-se de uma verdade moral. A segunda, uma verdade estéril e inútil que é geral e abstrata. Há ainda o "calar uma verdade" ou mentir, desde que não se fira a justiça.

Rousseau relaciona dois tipos de verdade à ficção: a que está limitada à fidelidade e a que está voltada para sua veracidade. Para ele, a fidelidade não deve guiar o relato, posto que a cautela utilizada, ao almejar ser fiel, é o contrário da verdade, porque aprisiona a imaginação e restringe o percurso da memória.

Podemos afirmar que não há uma distinção entre verdade e sinceridade, pois Rousseau não se dirige à verdade geral e abstrata, mas à verdade moral baseada no sentimento, no que ele chama de "instinto moral" e "consciência". . A sinceridade possui quatro fundamentos: as sensações, os sentimentos, a imaginação e a memória. A memória é reunida imaginação e a imaginação justifica a ausência de verdade na forma da ficção. É possível, assim, afirmar ser totalmente sincero, sem ser fiel às coisas.

A preocupação com a sinceridade significava educarse moralmente, na condição do dever ser. Se nem sempre é 
possível mostrar-se realmente como se é, aquele que assim procede, poderá tornar-se, talvez, o que deveria ser. Um dever ser que surge da sensibilidade, em Rousseau, da aproximação da natureza via a consciência moral. Um paradoxo aparente surge aqui, entre o ser que se sabe sincero, por natureza, e o ser que age na sociedade e, embora não seja sempre verdadeiro, busca sê-lo, ao menos no que tange à conduta justa.

Ao longo do século XIX, o gênero da autobiografia parece deslocar a pretensão de se ser sincero progressivamente para o tipo de escrita espontânea, principalmente a que se caracterizava como diário íntimo. Surgem teorias sobre a sinceridade, críticas e negativas, de forma a consolidar, ao longo do século XIX, uma derrocada da pretensão de transparência proclamada por Rousseau. Mas a preocupação do ser sincero persiste, mesmo entre os mais céticos.

Em meados do século XIX fala-se em graus de sinceridade, em sinceridade artística, opõe-se estilo e sinceridade. Podese afirmar um uso estratégico da insinceridade no início do século XX, nos diários do escritor francês André Gide, que remetem à artificialidade da escrita, à vaidade, ao abismo entre ser e aparecer. O insincero torna-se escravo da aparência, isto é, a insinceridade não é consciente. Mesmo sob o crivo negativo do insincero e imoral, a sinceridade não deixa de sobreviver em seu reverso como uma aspiração e dinamismo de poder tornar-se moral, em última instância.

\section{I - 0 RETORNO DO CONCEITO DE SINCERIDADE EM CONJUNÇÃO COM $O$ DE AUTENTICIDADE: LIONEL TRILLING E CHARLES TAYLOR}

Entre 1969 e 1970, Lionel Trilling ministra uma série de aulas na Universidade de Harvard, cujo resultado será a publicação do 
livro intitulado Sinceridade e autenticidade. Professor de língua inglesa de prestígio, com alunos que se tornaram conhecidos como Jack Kerouac e Allen Ginsberg, Trilling mescla filosofia e literatura em suas aulas, a fim de explorar a relação entre ética e conhecimento ou (re)conhecimento de si mesmo. Voltando ao período do Esclarecimento (ou Iluminismo), bem como à obra pré-moderna de Shakespeare, o autor se depara com o termo sinceridade, entendendo-o como um ideal moral. A reconfiguração da sinceridade como autenticidade, altera da antiga definição, o "permanecer verdadeiro a si mesmo". O modo de apresentação de suas aulas e, subsequentemente, da transcrição destas, é ensaístico, pontuado por incontáveis referências literárias, de Shakespeare a autores menos conhecidos. Os títulos direcionam a transformação da sinceridade em autenticidade: 1 . Sinceridade: sua origem e ascensão; 2 a alma honesta e a consciência dilacerada; 3 . o sentimento do ser e os sentimentos da arte; 4 . o heroico, o belo, o autêntico; 5 . sociedade e autenticidade; 6 . o inconsciente autêntico.

Tendo em vista que a palavra sinceridade e a preocupação em ser sincero nem sempre existiu em todas as culturas, Trilling lembra que a palavra em latim "sincerus", que provem de "sine cera", cujo significado relacionado com a cera pura mostraria sua transparência, só foi adotado pela língua inglesa no final do século XVI, após o uso desta em língua francesa (data-se o uso desde o século XIII). Sendo inicialmente utilizado não para pessoas, mas para objetos e materiais, como um vinho sincero ${ }^{6}$. A intenção do autor é mostrar como a sinceridade se tornou uma característica fundamental do homem ocidental durante séculos, marcado pela necessidade de afirmar-se leal e digno. Por outro lado, também é notável o declínio ou anacronismo do termo, sendo praticamente impossível não encontrar uma reação irônica 
diante da manifestação de sinceridade na contemporaneidade. $\mathrm{O}$ enfraquecimento é explícito nos usos de linguagem e na literatura.

Da origem ao declínio da sinceridade, a tese do autor não é exatamente descartar a sinceridade, mas mostrar que se houve uma desvalorização da palavra era porque ela não representava a verdade de alguém em si mesmo, mas servia como meio de apresentar alguém como sendo sincero. Portanto, em relação à subjetividade, a sinceridade não era um fim em si mesmo, mas um meio de reconhecimento social. A moralidade e a reputação no meio social parece, nesse sentido, retirar do sujeito a verdade sobre si mesmo, tornando-o refém da encenação do ser sincero social.

O peso dado ao contexto social no que tange à sinceridade como afirmação da subjetividade, é contrastado com o uso da palavra autenticidade no período da publicação da obra de Trilling. Ao definir autenticidade, o autor nos faz perceber um grau maior de exigência da verdade e do compromisso com a verdade do sujeito, baseado em uma não aceitação da perspectiva social que regeria a sinceridade.

A palavra 'autenticidade' vem tão facilmente na ponta da língua hoje em dia e possui tantas conexões que pode muito bem resistir aos esforços de definição como farei ainda, mas acho que por ora posso sugerir que se trata de uma experiência moral mais árdua do que a "sinceridade", uma concepção mais exigente de si mesmo e do que significa ser a ela verdadeiro, uma referência mais ampla para o universo e ao lugar do homem nele, e uma menor aceitação e visão cordial das circunstâncias sociais da vida. (TRILLING, 1972, p.11). ${ }^{7}$ 
Antes de se falar em autenticidade, portanto, Trilling afirma ter existido um domínio da sinceridade sobre a imaginação das pessoas de maneira a impor-lhes o que deveriam ser. A sinceridade de um indivíduo estava condicionada por seu papel na sociedade e suas crenças. Está relacionada também à confissão e ao desejo de ser sempre verdadeiro. Apesar de reconhecer esta fonte, à qual poderíamos relacionar Rousseau, o autor vê a afirmação da autenticidade ao usurpar o lugar da sinceridade nesta função, apenas em meados do século XIX, quando a noção moderna de identidade é, segundo diz, melhor definida.

Não por acaso, no capítulo seguinte - A alma honesta e a consciência dilacerada -, Trilling citará a interpretação de Hegel da obra de Diderot, publicada postumamente, intitulada $O$ sobrinho de Rameau. É no contraste entre as personagens do moralista e do imoralista, que se reconhece a inversão de papéis. O imoralista, o sobrinho velhaco do grande músico Rameau, deveria ser o degrau para que a fala do moralista expressasse a sinceridade de seu "dever ser". No entanto, ao leitor parece que o sobrinho, em vários momentos, mostra-se mais verdadeiro do que o filósofo moralista.

O tema da máscara presente na filosofia e na literatura do período, século XVIII, demonstra ser o melhor filtro de leitura do diálogo de Diderot, como representação do impessoal e da não sinceridade. Um jogo forçosamente aparente, reunido ao mundo do teatro, das convenções sociais, adereços e jogos de poder, que evocam a condição de alienação, desintegração ou dilaceração da consciência (para Hegel algo positivo, visto que a consciência desdobrada se torna mais capaz de se referir a si mesmo do que o eu ensimesmado).

Nos capítulos seguintes, Trilling relaciona as artes à autenticidade, por exemplo, ao mostrar como o espectador nota 
sua inautenticidade diante da obra de arte autêntica, seguindo um raciocínio de Sartre em A náusea. Nesta direção, o artista passa a servir como modelo de autenticidade. No âmbito social, em perspectiva marxista, a autenticidade passa a ser reconhecida na oposição ser e ter, mecânico e orgânico. Por fim, a relação entre autenticidade e psicanálise é pensada com base na crítica de Sarte à teoria de Freud e na reunião da perspectiva freudomarxista por Marcuse.

Podemos dizer que, em geral, a diferença marcada por Trilling entre sinceridade e autenticidade reside em distinguir, respectivamente, a apresentação de si aos outros, e expressão do verdadeiro eu no ajuizamento da relação com os outros.

Essa última função, a relação com os outros, parece ter fracassado, ao ser mantida limitada a um certo individualismo. Em resposta a este estreitamento e ao relativismo por ele gerado, Charles Taylor nos diz:

Em outras palavras, o relativismo era em si uma ramificação de uma forma de individualismo, cujo princípio seria algo como isto: todo mundo tem o direito de desenvolver sua própria forma de vida, baseada em seu próprio senso do que é realmente importante ou de valor. As pessoas são chamadas a ser verdadeiras consigo mesmas e a procurar sua própria auto-realização. Isto consiste em dizer que cada um deve, em última instância, determinar-se a si mesmo. Ninguém pode, ou deve, tentar ditar regras. (TAYLOR, 1991, p.14).

De acordo com este pressuposto, Taylor distingue três tipos de mal-estar no mundo contemporâneo: 1. O individualismo, cujo centramento do eu cria o que chama de sociedade permissiva e narcísica; 2 . O mal-estar que provem 
da primazia da razão instrumental, fortalecida pelo prestígio da tecnologia; 3. E a perda de liberdade política, aprisionada pela "gaiola de ferro" (iron-cage, expressão emprestada de Max Weber) da burocracia e do sistema capitalista.

Para desenvolver essas três perspectivas críticas, Taylor cita o conceito de autenticidade de Trilling e a distinção que este estabelece com a sinceridade, a fim de destacar a relação entre autenticidade e ética ${ }^{8}$. Autenticidade será entendida como um ideal moral, este é o seu pressuposto incial. E o que é um ideal moral? Segundo o autor: "O que quero dizer por um ideal moral? Quero dizer uma imagem do que seria um modo melhor ou mais elevado de vida, onde 'melhor' e 'mais elevado' não são definidos em termos do que desejamos ou necessitamos, mas oferece um padrão do que devemos desejar". (TAYLOR, 1991, p.23).

O pressuposto do ideal moral serve a Taylor como índice de negação ao considerar o narcisismo ou hedonismo. Ambos funcionariamsobaprerrogativada autenticidade, porém, esvaziada da força do ideal moral. Sua argumentação revela-se, portanto, na adoção do termo autenticidade, de forma a identificá-la com o ideal moral. Segundo afirma: "Acredito que a autenticidade deve ser levada à sério como um ideal moral" (TAYLOR, 1991, p.23).

Ao formular uma ética da autenticidade, Taylor revê teorias que remontam ao século XVIII, ao considerar em Descartes e Locke, formas de individualismo, no qual haveria uma racionalidade apartada do político (em Descartes), mesmo quando apresentada sob a perspectiva política (em Locke). A única perspectiva que romperia o individualismo da razão não engajada seria a do romatismo, ao manter um ideal de comunidade.

$\mathrm{Na}$ verificação das fontes do ideal moral reunido à autenticidade, Taylor retraça o tema da subjetividade moderna, 
como a descoberta da interioridade, desde a potencialidade do cogito em Santo Agostinho, à interioridade em Rousseau, para chegar ao princípio de originalidade em Herder. Rousseau recupera de Santo Agostinho não apenas o tema das "confissões", mas o espaço interior que rege a subjetividade apresentada no gênero narrativo da autobiografia. A diferença se estabelece na presença indireta de Deus, na descoberta da subjetividade por meio da narrativa em Santo Agostinho; substituída, em Rousseau, pela natureza ou pelo sentimento caracterizado como "amor de si". Com Herder, o ideal de autenticidade, quando cada um pode ser o que quiser, sem imitar outrem, associa-se ao princípio estético de originalidade, segundo o qual "ser verdadeiro a si mesmo, significa ser verdadeiro a sua própria originalidade" (Idem, p.29).

Tornando-se cada indivíduo uma existência criativa, cuja subjetividade se afirma pela autenticidade e pela originalidade, ainda esperamos pela relação com a alteridade. Nesse pressuposto, encontramos o "caráter dialógico" (Idem, p.33) da existência, que incorpora não apenas a linguagem em sua diversidade e níveis, mas também a percepção estética de outras linguagens: visuais, gestuais, artísticas. Não se trata, contudo, de um diálogo que se estabelece entre linguagens, mas um diálogo que, por meio das linguagens, alcança o senso comum. Para que a autenticidade tenha valor, ela deve ser reconhecida, ela deve poder fazer sentido para alguém e isto define, no relacionamento com a alteridade, o ideal moral que Taylor pretende a ela vincular. Quando a autenticidade não se estabelece em conjunto com o ideal moral via a alteridade, ela se torna solipsismo hedonista ou narcisismo.

Novamente, a filosofia de Hegel, em sua vertente fenomenológica, é buscada como recurso para fundamentação neste autor. Como interpreta Josef Frücht $\mathrm{l}^{9}$, “Taylor pretende demonstrar que - além do fato de que existe uma necessidade 
para os acontecimentos significantes, além do significado de autenticidade - há também, mais especificamente, a necessidade de unir-se aos outros". A fonte dessa demonstração é a teoria do "reconhecimento" na Fenomenologia do Espírito de Hegel.

O argumentação de Taylor retoma, portanto, a autenticidade associada ao ideal moral com validade. Dessa premissa resulta a segunda, a de que a subjetividade extrema deve ser rejeitada; unida a esta rejeição, nega-se igualmente a ideia de que a sociedade moderna equivale a um sistema aprisionador.

\section{III - SINCERIDADE, CONSCIÊNCIA MORAL E RETÓRICA NO SÉCULO XVIII}

Retomando nosso ponto de partida neste artigo, podemos avançar para a seguinte comparação: de um lado, a subjetividade aliada ao senso ou consciência moral; de outro, uma perspectiva cética aliada à ironia.

As filosofias do século XVIII, particularmente no contexto britânico e francês, condicionavam o estético ao ético por meio do sentimento intuitivo do certo e do errado, e do sentimento que resulta no juízo estético (ou gosto) do belo ou disforme. Reconhecemos os termos dessa discussão em vários autores do período, mas se lembrarmos particularmente de Hume e de seu ensaio Do padrão do gosto, podemos perceber, paradoxalmente, a presença e a negação do ceticismo. Não existe, certamente, um acordo entre as teorias, mas pode-se identificar na afirmação de uma "voz interna" relativa à presença ou de Deus, ou da ideia de Bem, ou da natureza, ou o que possa conferir um sentimento de pertencimento a um ser integral. Deísmo ou teísmo, natureza ou bem comum, abre-se, com isso, um espaço de interioridade prioritariamente sensível. A voz da natureza é expressada como um instinto divinal que se torna a origem 
da consciência moral em Rousseau. Por isso, ele pode dizer que conhece a si mesmo pelo sentimento. No entanto, Rousseau não nega a corrupção das paixões sob o ensejo do "amor próprio" ou, se quisermos, da vaidade, uma espécie de sentimento proveniente da experiência social eficaz na alienação da orientação da voz interior da natureza.

O grande mérito do século XVIII, portanto, foi conferir moralidade à existência interior que nos torna diferentes uns dos outros, mas não separados uns dos outros. O perigo, por assim dizer, reside no jogo alienante e alienador do sentimento moral interno, na relação com o convívio social e externo. Por isso, o compromisso de ser verdadeiro consigo mesmo, de buscar a auto-realização por meio da afirmação da autenticidade e da originalidade da existência individual, não pode ser relegado da prática social. Bem como, não se pode imergir no sentimento de auto-realização sem a necessária inserção social que rege o ideal moral da autenticidade.

A sinceridade aparece ainda, no contexto do século XVIII, com ênfase retórica, uma recuperação do tema de discussão da antiguidade sobre o domínio do sentimento para potencialidade da expressão. O retórico equivale ao ator ao expressar sua emoção sinceramente. Eis aqui um momento em que a eloquência e o poder de expressão se constitui como uma encenação teatral. "Considera-se que o que distingue a pessoa 'natural' de uma pessoa 'artificial' é que a primeira possui um poder sob suas próprias palavras e ações (...) Uma grande máscara permite a alguém possuir, como sua própria face, outra máscara". (Stephen Greenblatt, "Pyschoanalysis and Renaissance Culture", apud KORTHAL ALTES, 2014, p. 393). A encenação e o jogo de máscaras presente no período faz oscilar o valor da sinceridade, que passa a ser vista como elaboração retórica, cuja origem é religiosa. 
A fala do coração ensaiada, já havia adquirido importância no contexto religioso com a Reforma protestante. Calvino ${ }^{10}$ possuia como moto: Prompte et sincere. O que poderia ser traduzido com maior ênfase retórica por "abertamente e sinceramente", ou por "pronto e sincero". A frase completa é: "Cor meum tibi offero, Domine, prompte et sincere" (O meu coração te ofereço, ó Senhor, de modo pronto e sincero). O movimento contrário a este emblema de abertura do coração e da sinceridade, é o engano, a vaidade e a dissimulação. É possível ler nas entrelinhas que a inspiração rousseniana possui um modelo em Santo Agostinho e outro em Calvino, embora se afirme com distanciamento em relação às duas religiões cristãs. Rousseau entremeia o contexto da Reforma religiosa e a adoção de valores protestantes de sinceridade e transparência após a Revolução Francesa. São conhecidas as conexões estabelecidas entre Igreja e nobreza por meio de caricaturas que revelam, nas máscaras socias, a hipocrisia e a dissimulaçã $0^{11}$, que se constitui como o inautêntico. Haveria um valor moral no inautêntico?

\section{IV - O CONTRAPONTO DO INAUTÊNTICO E SUA FUNÇÃO MORAL: A IRONIA. UM FILME COMO EXEMPLO.}

Um dos caminhos conhecidos para falar sobre a ironia pode ser traçado desde Sócrates aos céticos aos retóricos do século II d.C., chegando ao Renascimento e à configuração do discurso jocoso e sério empregado por filósofos como Erasmo de Rotterdam e Thomas More, com inspiração nos retóricos da antiguidade. À parte a interpretação que Hegel faz do diálogo O sobrinho de Rameau de Diderot, é possível também ressaltar 
a função irônica como um contraponto à fala do moralista e à inversão de papéis, como já comentamos anteriormente. Pode-se indicar a ironia no contexto do Romantismo alemão ou a ironia kierkegaardiana, sobre cujas diferenças não podemos abarcar neste artigo. No entanto, o que nos importa ora lembrar é que a ironia também é apresentada como um valor pós-moderno, e que a chamada "nova sinceridade", justamente, vem a ela se opor.

O individualismo alienado e narcísico alcança expressão cultural no cinema, e outros meios, de maneira mais ou menos explícita. Transformam-se naquilo que Josef Frücht ${ }^{12}$ batiza de "heroismo cool", cujos personagens são marcados por uma indefinibilidade e uma autoreferencialidade. "Cool is cool" é a afirmação tautológica que permite a Früchtl ressaltar a identidade do que considera ser um dos tipos de heroísmo moderno, tal como se apresenta na representação cultural do cinema no gênero dos filmes de gângsteres. Nota-se na atitude "cool" uma indiferença e mesmo desprezo pelo mundo com um lastro de ironia. Tendo como repertório teórico a obra de Lionel Trilling, Walter Benjamin, Richard Rorty, Georg Simmel e Helmuth Plessner, Früchtl busca na definição de cool a condição de um fenômeno estético manifestado em alguns personagens cinematográficos americanos que melhor caracterizam a indiferença regrada pela ironia.

Temos em vista que no terreno da "nova sinceridade" é praticamente impossível falar de "sinceridade" sem perceber o lastro de ironia que a acompanha. A distinção com a palavra "autenticidade", no entanto, auxilia a elaborar a distinção sobre a qual nos detivemos no início do artigo. A sinceridade reunida à ironia é mostrada ora de maneira hiperbólica, ora de maneira "indiferente", "legal", "descolada" - palavras que poderiam, no conjunto, traduzir o significado de cool. O que 
percebemos aqui é sempre uma voz dupla. Não mais a voz da natureza, mas uma operação dialógica entre o crédito e o descrédito que se confere à subjetividade. O que se sugere é que a ironia não é mais de ordem intelectual, como no romantismo, mas fundanda no sentimento, como se fosse naturalizada.

Tendo isso em vista, tomaremos como exemplo um movimento caracterizado pela "nova sinceridade" e uma produção deste. Trata-se do movimento dinamarques conhecido como Dogma 95, que reuniu inicialmente os cineastas Lars von Trier e Thomas Vinterberg. À maneira das vanguardas artísticas do início do século XX, eles lançaram um manifesto em 13 de março de 1995. Nem sempre identificado com a "nova sinceridade", mas com um certo realismo e rejeição ao filme de tipo hollywoodiano, os autores do manifesto estipularam dez regras. De um lado, regras técnicas, nas quais restringiam efeitos especiais e uso excessivo de recursos tecnológicos; de outro, regras éticas, tendo em vista o conteúdo dos filmes. Outras quatro regras foram acrescentadas posteriomente. $\mathrm{O}$ primeiro resultado apresentado foi Festen (traduzido por Festa em família) do diretor Vinterberg; o segundo, de Lars von Trier, foi Idioterne (Os idiotas).

O título conferido ao manifesto, contrário à super produção de filmes, foi "Voto de castidade"13. As regras não só repetem algumas características de movimentos europeus do cinema da segunda metade do século XX, como o "neorrealismo italiano", a "nouvelle vague francesa", ambos importantes para os movimentos do "cinema novo" e "cinema marginal" brasileiros -, como incorporam a atitude de vanguarda artística ao publicarem manifestos. A identidade apregoada pode ser entendida como performática, 
mas adequa-se com clareza ao tema da autenticidade isolada, em princípio, da ética e da política. O grupo apresentado no filme corresponde à geração pós-68, cujos arroubos de independência, transformações de valores e politização, determinaram um valor de autenticidade integrado ao social. No filme existe a atitude, cujo vínculo político está desfeito. Podemos verificar neste estado, o significado de dilaceração da consciência e a recuperação da ironia como inversão de papéis, por meio de uma mímica imitadora e grotesca da atitude política da geração três décadas distante da que se apresenta no filme.

No jogo entre autenticidade $\mathrm{e}$ inautenticidade da subjetividade posta em cena, os recursos técnicos (e seus imperativos morais) revelam que o pressuposto de autenticidade parece haver encontrado seu limite. Este limite, no entanto, é expresso por uma espécie de "sinceridade da forma". Há quem suspeite da sinceridade dos manifestos do cinema periférico à indústria hollywoodiana, como se encobrissem uma deficiência econômica a fim de publicizar suas obras. Isto tornaria igualmente suspeitos os espectadores desses filmes, cujo engajamento político parte do conhecimento da proposta estética reunida à política, acreditando tratar-se de originalidade e não de um produto de publicidade de mercado. Aos menos, é o que se entende da relação entre manifesto e autenticidade moral e política das vanguardas da geração de 1960. Se entendermos que o Dogma95 ironiza também a forma, apresentada nos dez itens do manifesto, ficaremos apenas com a performance, como o único elemento de originalidade, descartando tanto a sinceridade, quanto a autenticidade, reveladas na reunião entre subjetividade, moral e política. 


\section{CONSIDERAÇÕES FINAIS}

À guisa de conclusão, éimportante ainda comentar o caráter cultural regional não só das representações artísticas, mas da própria requisição de "sinceridade" e de "autenticidade". O pressuposto de sinceridade, como vimos em sua manifestação no século XVIII, está profundamente relacionado ao tema da subjetividade moderna. Entretanto, sua requisição surge com mais clareza no contexto francês, possuindo certamente em Rousseau seu maior alicerce. Há intérpretes que afirmam ter Rousseau contaminado toda a cultura francesa com este pressuposto de sinceridade ao longo do século XIX e início do século XX, como se cada autor - particularmente os filósofos e literatos ou homens de letras -, tivessem que necessariamente passar pela agrura de se posicionar a favor ou contra a sinceridade, criando adjetivações como a de "sinceridade artística" em Baudelaire, ou eliminando o tema da sinceridade-fidelidade, como Flaubert ao responder ironicamente às indagações de quem seria na realidade sua personagem Madame Bovary, dizendo “c'est moi!".

$\mathrm{Na}$ Alemanha contemporânea à época de Rousseau, vemos seu grande representante da cultura, Goethe, escrever também uma autobiografia - Poesia e verdade - sem demonstrar a menor preocupação em ser ou apresentar-se sinceramente. A sinceridade não é uma questão neste contexto. A "nova sinceridade" surge com clareza no contexto cultural da América do Norte e na Rússia ${ }^{14}$. O tema se expandiu nas artes, particularmente na literatura, na música e filmes, sendo possível reconhecer alguma teorização em manifestos que mostram claramente a ironia na reutilização do termo ${ }^{15}$. Há uma variação de significados que distanciam a sinceridade moderna e seus propósitos das manifestações que 
se apresentam, além da forma ironizada, pela espontaneidade ou pela performance ensaiada.

Quanto às teorias de Trilling e Taylor, podemos notar a revisão do sentido da sinceridade, ao lado do sentido de ironia, ambas relacionadas ao tema da subjetividade moderna. Em ambos, a palavra autenticidade passa a ser uma ampliação da sinceridade em sua inserção social e na função de reconhecimento da alteridade.

Finalmente, a nova sinceridade expõe um cansaço com um certo tipo de ironia, representado pela indústria cultural em suas modalidades midiáticas. Sem assumir o termo com seriedade, como se fosse um novo compromisso com a verdade ou com o ideal de moralidade, a nova sinceridade explora, ironicamente, os aspectos sedutores e ideológicos da espetaculirização, da publicização da imagem, geradas pela indústria do divertimento, no contexto norte-americano. No contexto pós-soviético, sua função crítica se revela no desmonte da propaganda ideológico-política do Estado Soviético, e auto-ironiza o sentimento de espontaneidade atribuído aos russos. Neste sentido, a representação artística da nova sinceridade nestes dois contextos culturais parece alcançar a originalidade que se espera em expressão de ordem também política.

\section{NOTAS}

${ }^{1}$ Professora adjunta da Faculdade de Filosofia da Universidade Federal de Goiás (FAFIL-UFG), na qual é responsável pela disciplina de Estética. Participa do Programa de Pós-Graduação da FAFIL. Formada em Filosofia 
pela Pontifícia Universidade Católica de São Paulo (graduação e mestrado) e Unicamp (doutorado), tendo sido bolsista do convênio DAAD-Capes, durante o doutorado, na Universidade Livre de Berlim. Concluiu seu pós-doutorado na Universidade de Amsterdã (UvA). Coordenou o GT de Estética da Associação Nacional de Pós-Graduação em Filosofia (ANPOF) e é participante da Associação Brasileira de Estética (ABRE) e da Associação Brasileira de Estudos do Século XVIII (ABES18). É coordenadora do Grupo de Estudos Kinosophia, relativo à Filosofia do Filme e desenvolve atualmente uma pesquisa sobre as teorias do gosto no século XVIII britânico que marcam o surgimento de questões fundamentais e constituintes da Estética. Publicou o livro "Sobre o declínio da sinceridade. Filosofia e autobiografia de Jean-Jacques Rousseau a Walter Benjamin” (Loyola, 2006) e vários artigos em revistas acadêmicas.

${ }^{2}$ Nesta introdução sobre o conceito moderno de sinceridade, utilizaremos como referência, de maneira sucinta, o trabalho já publicado sobre o assunto no livro da autora intitulado Sobre o declínio da "sinceridade". Filosofia e autobiografia de Jean-Jacques Rousseau a Walter Benjamin, publicado pela Editora Loyola em 2006,

${ }^{3}$ Epígrafe das Confissões, retirada de um poema de Píndaro: "interiormente e sob a pele".

${ }^{4}$ Máxima retirada de um verso da obra Sátiras de Juvenal (IV, 9), foi tornada divisa moral por Rousseau em 1758, em Carta a d'Alembert: "Consagrar a vida à verdade".

${ }^{5} \mathrm{Cf}$. Emílio ou Da Educação, particularmente o Livro IV.

${ }^{6}$ Cf. L. Trilling, p.12-13.

${ }^{7}$ As traduções dos textos de Lionel Trilling e Charles Taylor são de responsabilidade da autora deste artigo.

${ }^{8}$ Cf. C. Taylor, p.11.

${ }^{9}$ J. Früchtl, Anotações de aulas do Seminário Filme e Filosofia, Universidade de Amsterdã, 2015.

${ }^{10} \mathrm{Cf}$. Liesbeth Korthals Altes, Ethos and Narrative Interpretation: The Negotiation of Values in Fiction (Frontiers of Narrative). Capítulo 6 "Sincerity and Other Ironies", p. 390-473,

${ }^{11}$ Choderlos de Laclos e seu romance epistolar de 1702, Les liaisons dangereuses (Ligações perigosas), tornou-se uma referência deste tipo de caricatura social. ${ }^{12}$ Cf. C. M. Damião, E. L. G. Prado, J. Teles Silva, J. Neves de Campos e T. 
Trizoli. "O eu impertinente: romantismo, eu agonal e filme de gângster", Revista Inquietude, Goiânia, vol. 3, n 2, ago/dez 2012, p.265-263.

${ }^{13}$ De acordo com Sávio Leite e Silva, in: Dogma95: Tudo é angústia, p.1619. "1. Filmar em locações reais e abolir o uso de cenários, se algum objeto é necessário para o desenvolvimento da história, deve-se buscar uma localização onde existem esses objetos. Não pode haver deslocamento de cidade. A equipe de filmagem gravará na mesma localização proposta pelo roteiro, uma vez que se deve usar aquilo que for encontrado. 2. Usar somente o som direto gravado, ficando vedado o uso de trilha sonora. $\mathrm{O}$ som não pode ser separado da imagem. (...) Nada de misturas e sincronizações. 3. Não usar tripé. A câmera deve estar na mão ou nos ombros. Esse é um ponto espectral da história do cinema: o Cinema-Verdade. Antes da Nouvelle Vague, isso de levar a câmera no ombro deixava-se para os amadores e para os excêntricos." 4. Não usar iluminação artificial. O filme deve ser colorido. Se uma luz não é suficiente para rodar determinada cena, esta deve ser eliminada ou, a rigor, pode-se ligar uma pequena luz à câmera. A cor é uma norma na indústria e algo essencial para aquilo que denominamos realismo, enquanto que o preto-e-branco se parece com um desenho, uma concessão e também porque é muito caro. O diretor de fotografia deve se arrumar com a luz que tem. 5. Não usar filtros e trucagens. Nada de fundos desenhados de cadeias de montanhas, nem de naufrágios. Não se devem usar algo de gelatina e filtros de baixo contraste. 6. Não usar ação superficial (assassinatos, lutas corporais, armas de fogo). 7. O Dogma95 proíbe tanto os filmes históricos como viagens no espaço, os filmes deverão ter que falar necessariamente sobre o seu tempo. 8. "Os filmes de gênero são inaceitáveis" - uma proibição imensa fechada em seis míseras palavras. Depois da invenção e da codificação de cada gênerocomédia, western, terror, cine negro, infantil - que foram vitais para a popularização mundial do cinema, o Dogma95 pretende desprezar esse fato. 9. O formato final de exibição deve ser em $35 \mathrm{~mm}$. Um gesto folclórico para com a história. As medidas da Academia eram de 1:33 x 1, como nos tempos do velho cinema mudo. O Dogma95 obriga também cada um a esquecer do largo beneficio da qualidade de gravação com câmeras $35 \mathrm{~mm}$. A forma de casamento do vídeo digital e seu processo de transformação em película $35 \mathrm{~mm}$ ainda está em processo de aperfeiçoamento. Essa regra só é aplicada quanto ao formato de distribuição, para que se possa filmar em vídeo ou 
$16 \mathrm{~mm}$ e distribuir em $35 \mathrm{~mm}$. 10. O diretor não será creditado na película. $\mathrm{O}$ fato dele não poder aparecer nos créditos é um pouco duro, tendo em conta a quantidade desmedida de pessoas que aparecem nos créditos por costume e dada a aceitação geral da sua posição como presença criativa dominante no filme, quase como um autor".

${ }^{14} \mathrm{~A}$ este respeito, confira-se o livro de Ellen Rutten - Sincerity after comunism. A cultural history - a ser lançado em breve, cujos títulos de cada capítulo sugerem a importância da sinceridade no contexto: "Introduction: Sincerity, Memory, Marketing, Media; Chapter 1 History: Situating Sincerity; Chapter 2 "But I want Sincerity So Badly!": The Perestroika Years and Onwards; Chapter 3 "I Cried Twice": Sincerity and Life in a Post-Communist World; Chapter 4 "So New Sincerity": New Century, New Media". O acesso ao manuscrito se deu em palestra da professora Ellen Rutten na Universidade de Amsterdã em 2015.

${ }^{15}$ Leia-se, por exemplo o que diz parte do Manifest for the New Sincerity: "What is The New Sincerity? Think of it as irony and sincerity combined like Voltron, to form a new movement of astonishing power. Or think of it as the absence of irony and sincerity, where less is (obviously) more. If those strain the brain, just think of Evel Knievel. Let's be frank. There's no way to appreciate Evel Knievel literally. Evel is the kind of man who defies even fiction, because the reality is too over the top. Here is a man in a red-white-and-blue leather jumpsuit, driving some kind of rocket car. A man who achieved fame and fortune jumping over things. Here is a real man who feels at home as Spidey on the cover of a comic book. Simply put, Evel Knievel boggles the mind”. (Fonte: http://www. maximumfun.org/blog/2006/02/manifesto-for-new-sincerity.html) 


\section{REFERÊNCIAS}

DAMIÃO, Carla M. Sobre o declínio da "sinceridade". Filosofia e autobiografia de Jean-Jacques Rousseau a Walter Benjamin. São Paulo, Ed. Loyola, 2006.

DAMIÃO, C.M./ PRADO, E. L. G./ TELES SILVA, J/ NEVES DE CAMPOS. J./ TRIZOLI, T. "O eu impertinente: romantismo, eu agonal e filme de gângster", Revista Inquietude, Goiânia, vol. 3, n 2, ago/dez 2012, p.235-263.

FRÜCHTL, J. Das unverschämte Ich. Eine Heldengeschichte der Moderne. Frankfurt a.M., Suhrkamp, 2004.

FRÜCHTL, J. The impertinent Self. A heroic history of Modernity. Translated by Sarah L. Kirby. Stanford/California, Stanford University Press, 2009.

KORTHALS ALTES, Liesbeth. Ethos and Narrative Interpretation: The Negotiation of Values in Fiction. University of Nebraska Press, 2014.

LAMARQUE, P and S. H. OLSEN (1994). Truth, Fiction and Literature. (Oxford: Oxford University Press).

MORAN, R. (2005). 'Problems of Sincerity'. Proceedings of the Aristotelian Society 105: pp. 325-345.

PEYRE, Henri. Literature and Sincerity. New Haven/London, Yale University Press, 1963.

ROBERTS, John. "Dogme 95”, New Left Review I/238, November-December 1999, p. 141-149. 
ROSENBAUM, Susan B. Professing Sincerity. Modern Lyric Poetry, Commercial Culture, and the Crisis in Reading. University Virginia Press, 2007.

ROUSSEAU, Jean-Jacques. As Confissões. Tradução: Rachel de Queiroz. 2. ed. São Paulo: Atena Editora, 1959. v. 1.

ROUSSEAU, Jean-Jacques. Júlia ou A Nova Heloísa. Tradução Flávia N. L. Moretto. São Paulo: Editora Ática, 1994.

ROUSSEAU, Jean-Jacques. Os devaneios do caminhante solitário. Tradução Fúlvia Maria Luiza Moretto. Brasília: Editora da UnB, 1995.

SILVA, Fábio Leite. Dogma 95: tudo é angústia. Belo HorizonteMG, Escola de Belas Artes / UFMG, 2007. Dissertação de Mestrado.

STAROBINSKI, Jean. A transparência e o obstáculo: seguido de sete ensaios sobre Rousseau. São Paulo. Tradução: Maria Lúcia Machado. Companhia das Letras, 1991.

TAYLOR, Charles. The Ethics of Authenticity. Cambridge/ Massachusetts/London, Harvard University Press, 1991.

TRILLING, Lionel. Sincerity and Authenticity. Cambridge/ Massachusetts/London, Harvard University Press, 1971. 